\title{
THE ESTIMATION OF TRANSPIRATION FROM SPARSE DRYLAND MILLET USING STOMATAL CONDUCTANCE AND VEGETATION AREA INDICES
}

\author{
J.S. WALLACE ${ }^{1}$, J.M. ROBERTS ${ }^{1}$ and M.V.K. SIVAKUMAR ${ }^{2}$ \\ IInstitute of Hydrology, Wallingford, Oxon. OX $108 B B$ (U.K.) \\ ${ }^{2}$ ICRISAT Sahelian Center, BP 12404, Niamey (Niger)
}

(Received August 7, 1989; revision accepted November 15, 1989)

\section{ABSTRACT}

Wallace, J.S., Roberts, J.M. and Sivakumar, M.V.K., 1990. The estimation of transpiration from sparse dryland millet using stomatal conductance and vegetation area indices. Agric. For. Meteorol., 51: 35-49.

The stomatal conductances of the leaves and panicles of a sparse dryland millet crop grown fat ICRISAT Sahelian Center, Sadoré, in southwest Niger were measured using a diffusion porometer and an infrared gas analyser, respectively. Leaf conductances were found to be high, up to $12 \mathrm{~mm}$ $\mathrm{s}^{-1}$ or $480 \mathrm{mmol} \mathrm{m}{ }^{-2} \mathrm{~s}^{-1}$, and varied according to the leaf surface, age and position in the canopy. These data were combined with measurements of leaf area index to calculate canopy conductance. Because of the low leaf area (maximum 1.3), canopy conductances were low and varied both diurnally and seasonally. Transpiration was calculated using the above canopy conductance values using the Penman-Monteith and Shuttleworth-Wallace models. In comparison to the Shuttleworth-Wallace model, it was found that the Penman-Monteith equation underestimated transpiration when the soil was dry and overestimated it when the soil was wet. These differences in transpiration arise because of the modification of the in-canopy vapour pressure deficit caused by heat and water vapour fluxes from the soil, a mechanism which is only present in the Shuttleworth-Wallace model.

\section{INTRODUCTION}

Dryland crop yields in the semi-arid regions of Africa are poor and variable as a result of the erratic and low rainfall. However, within a given season, differences in yield may occur according to the proportion of the rainfall used by the crop in transpiration. Therefore, in order to fully understand differences in crop growth and to develop production systems for yield maximization, it is necessary to know the amount of transpiration from a crop. Transpiration can be deduced from total evaporation if soil evaporation is known (e.g. see Cooper et al., 1983; Allen, 1990). Alternatively, transpiration can be estimated more directly from measurements of stomatal conductance and leaf area index, which 
give a measure of the conductance of the entire canopy. This canopy conductance can then be used with weather data in a combination equation, such as that of Monteith (1965), to deduce transpiration. However, this combination equation was derived for use in complete, closed canopies with no soil evaporation and is not necessarily applicable to sparse canopies where substantial fluxes of heat and water vapour can arise at the soil surface (Shuttleworth and Wallace, 1985; Choudhury and Monteith, 1988).

This paper presents some measurements of stomatal conductance in a sparse dryland millet grown in the hot, semi-arid environment of south-west Niger. The diurnal behaviour and relative values of the different leaves and panicles are illustrated. Canopy conductances were computed from these measurements and transpiration was calculated using the two different versions of the combination equation given by Monteith (1965) and Shuttleworth and Wallace (1985).

\section{MATERIALS AND METHODS}

\section{Site, crop and season}

The site was at Sadore $\left(13^{\circ} 15^{\prime} \mathrm{N} ; 2^{\circ} 17^{\prime} \mathrm{E}\right)$, the experimental farm of the International Crops Research Institute for the Semi-Arid Tropics (ICRISAT) Sahelian Center, located $45 \mathrm{~km}$ south of Niamey, Niger. Further details are given by Shuttleworth et al. (1988). The crop studied was millet (Pennisetum americanum cv. 'CIV'T') which was planted in rows $0.75 \mathrm{~m}$ apart and thinned to a density of 30000 plants ha $^{-1}$. The soil was Daybou sand about $2-3 \mathrm{~m}$ deep over laterite gravel (see West et al., 1984).

The climate of the site is typical of the southern edge of the Sahelian zone with summer rainfall and high temperatures throughout the year. Annual potential evaporation of $2046 \mathrm{~mm}$ at Niamey is nearly four times the mean annual rainfall of $562 \mathrm{~mm}$ (Sivakumar, 1987). In 1986 rainfall was about 10\% above average and in 1987 the rains were very late and $20 \%$ below average.

\section{Stomatal conductance}

Stomatal conductance of the leaves was measured with an automatic diffusion porometer (AP3, Delta-T Devices, Cambridge, U.K.) ${ }^{1}$ on 5 days in 1986 and 2 days in 1987 . On each day stomatal conductance measurements were made at 2-h intervals, between dawn and dusk, on all the green leaves on five randomly selected plants. When the number of leaves per plant exceeded six, measurements were made on alternate leaves along the stems. Measurements

${ }^{1}$ Trade names are included for the benefit of the reader and imply no endorsement or preferential treatment of the products used by the Institute of Hydrology or ICRISAT. 
were made on both leaf surfaces about half-way along the leaves. Before each set of measurements the porometer was switched on and allowed to equilibrate in the shade for $10 \mathrm{~min}$ with the sensor head attached to the calibration plate. The porometer was recalibrated after every run.

After the panicles had emerged, their conductances were measured using an infrared gas analyser (model LCA2, The Analytical Development Co. Ltd., U.K.). Measurements were made mid-way along five panicles selected to represent the panicle age distribution found in the crop on any particular day. To check for any instrumental differences in the conductances measured using the IRGA and the diffusion porometer both instruments were used to measure leaf stomatal conductances on a number of days and no large systematic instrumental bias was observed.

\section{Canopy conductance}

Canopy conductance $\left(g_{\mathrm{s}}^{c}\right)$ was calculated from stomatal $\left(g_{\mathrm{s}}\right)$ and panicle $\left(g_{\mathrm{p}}\right)$ conductances using the formula

$g_{\mathrm{s}}^{\mathrm{c}}=\left(r_{\mathrm{s}}^{\mathrm{c}-1}\right)=\pi P A I \cdot g_{\mathrm{p}}+\sum_{\mathrm{i}} L A I_{\mathrm{i}}\left\{g_{\mathrm{si}}^{\mathrm{u}}+g_{\mathrm{si}}^{\mathrm{l}}\right\}$

where: $r_{\mathrm{s}}^{\mathrm{c}}$ is the canopy resistance; $L A I_{i}$ is the area index of a given leaf; $g_{\mathrm{si}}^{\mathrm{u}}$ and $g_{\mathrm{si}}^{\mathrm{l}}$ are the stomatal conductances of its upper and lower sufaces; and $P A I$ is the projected area index of the panicle. Leaf area indices were measured using samplestaken every 7-10 days, the projected foliage area index being measured using a leaf area meter ( $\mathrm{Li}-3100, \mathrm{Li}-\mathrm{COR}$ Inc., U.S.A.). Panicle area indices were calculated from measurements of seed head length, diameter and number per unit ground area.

\section{Transpiration}

Two methods were used to calculate transpiration. Firstly, the Monteith version of the Penman equation (Monteith, 1965) was used to calculate transpiration from the millet canopy $\left(E_{\mathrm{c}}\right)$. The equation has been modified so that the energy available for transpiration is given by the difference between the available radiative energy above the crop, $A$, and the available energy at the soil surface, $A_{\mathrm{s}}$. This gives an equation of the form

$\lambda E_{\mathrm{c}}=\frac{\Delta\left(A-A_{\mathrm{s}}\right)+\rho c_{\mathrm{p}} D / r_{\mathrm{a}}}{\Delta+\gamma\left\{1+\left(\mathrm{r}_{\mathrm{s}}^{\mathrm{s}} / \mathrm{r}_{\mathrm{a}}\right)\right\}}$

where: $c_{\mathrm{p}}$ is the specific heat of air at constant pressure; $r_{\mathrm{a}}$ is the aerodynamic resistance; $D$ is the vapour pressure deficit; $\Delta$ is the rate of change of saturated vapour pressure with temperature; $\lambda$ is the latent heat of vaporization of water; 
$\rho$ is the density of air; and $\gamma$ is the psychrometric constant. The available energy at the soil surface, $A_{\mathrm{s}}$, is given by

$A_{\mathrm{s}}=R_{\mathrm{n}}^{\mathrm{s}}-G$

where $R_{\mathrm{n}}^{\mathrm{s}}$ is the net radiation at the soil surface, and $G$ is the flux of heat in the soil. The net radiation below the crop canopy was measured using four tube net radiometers (Type TRL, Delta-T Devices, Cambridge, U.K.) mounted 15$20 \mathrm{~cm}$ above the soil surface. The radiometers were placed such that each traversed one row of the crop. A fifth tube net radiometer was mounted above the crop at $4.5 \mathrm{~m}$ at the same orientation as those below the canopy. From these measurements of net radiation above and below the millet crop, it was found that $R_{\mathrm{n}}^{\mathrm{s}}$ could be calculated using a Beer's Law relationship of the form

$R_{\mathrm{n}}^{\mathrm{s}}=R_{\mathrm{n}} \exp \left\{-K_{\mathrm{n}}(L A I+P A I)\right\}$

where $R_{\mathrm{x}}$ is the net radiation measured above the crop canopy, and $K_{\mathrm{n}}$ is the extinction coefficient for net radiation with a mean value of 0.41 . Hourly values of the soil heat flux $G$ were measured using five heat flux plates (Thornwaite Associates, U.S.A.) buried $5 \mathrm{~mm}$ below the surface diagonally from one ridge to the next ridge. With flux plates at this shallow depth, errors in soil heat flux owing to changes in heat storage above the plates is small $(<10 \%)$ and, therefore, no corrections were made to the recorded values.

The second method for calculating $\lambda E_{\mathrm{c}}$ is that derived for sparse crops by Shuttleworth and Wallace (1985). To maintain consistency with that paper we chose to use resistances rather than conductances, in which case the total evaporation from soil plus plants, $\lambda E$, is given by

$-\lambda E=C_{\mathrm{c}} \mathrm{PM}_{\mathrm{c}}+C_{\mathrm{s}} \mathrm{PM}_{\mathrm{s}}$

where $\mathrm{PM}_{\mathrm{c}}$ and $\mathrm{PM}_{\mathrm{s}}$ are terms each similar to the Penman-Monteith combination equations which would apply to evaporation from a closed canopy and from bare soil, respectively. They have the form

$\mathrm{PM}_{\mathrm{c}}=\frac{\Delta A+\left[\rho c_{\mathrm{p}} D-\Delta r_{\mathrm{a}}^{\mathrm{c}} A_{\mathrm{s}}\right] /\left(r_{\mathrm{a}}^{\mathrm{a}}+r_{\mathrm{a}}^{\mathrm{c}}\right)}{\Delta+\gamma\left\{1+r_{\mathrm{s}}^{\mathrm{c}} /\left(r_{\mathrm{a}}^{\mathrm{a}}+r_{\mathrm{a}}^{\mathrm{c}}\right)\right\}}$

$\mathrm{PM}_{\mathrm{s}}=\frac{\Delta A+\left\{\rho c_{\mathrm{p}} D-\Delta r_{\mathrm{a}}^{\mathrm{s}}\left(A-A_{\mathrm{s}}\right)\right\} /\left(r_{\mathrm{a}}^{\mathrm{a}}+r_{\mathrm{a}}^{\mathrm{s}}\right)}{\Delta+\gamma\left\{1+r_{\mathrm{s}}^{\mathrm{s}} /\left(r_{\mathrm{a}}^{\mathrm{a}}+r_{\mathrm{a}}^{\mathrm{s}}\right)\right\}}$

The coefficients $C_{\mathrm{c}}$ and $C_{\mathrm{s}}$ are given by the expressions

$C_{\mathrm{c}}=\left\{1+R_{\mathrm{c}} R_{\mathrm{a}} / R_{\mathrm{s}}\left(R_{\mathrm{c}}+R_{\mathrm{a}}\right)\right\}^{-1}$

and

$C_{\mathrm{s}}=\left\{1+R_{\mathrm{s}} R_{\mathrm{a}} / R_{\mathrm{c}}\left(R_{\mathrm{s}}+R_{\mathrm{a}}\right)\right\}^{-1}$

where: 


$$
\begin{aligned}
& R_{\mathrm{a}}=(\Delta+\gamma) r_{\mathrm{a}}^{\mathrm{a}} \\
& R_{\mathrm{s}}=(\Delta+\gamma) r_{\mathrm{a}}^{\mathrm{s}}+\gamma r_{\mathrm{s}}^{\mathrm{s}} \\
& R_{\mathrm{c}}=(\Delta+\gamma) r_{\mathrm{a}}^{\mathrm{c}}+\gamma r_{\mathrm{s}}^{\mathrm{c}}
\end{aligned}
$$

A full description of the terms is given by Shuttleworth and Wallace (1985). The aerodynamic resistances associated with the soil, canopy and air above the crop ( $r_{\mathrm{a}}^{\mathrm{s}}, r_{\mathrm{a}}^{\mathrm{c}}$ and $r_{\mathrm{a}}^{\mathrm{a}}$, respectively) were calculated from crop height, windspeed and leaf area index according to the formulae given by Shuttleworth and Wallace (1985). When using the modified Penman-Monteith formulae, eqn. (2), the aerodynamic resistance $r_{\mathrm{a}}$ was calculated as the sum $r_{\mathrm{a}}^{\mathrm{c}}+r_{\mathrm{a}}^{\mathrm{a}}$.

When both soil and canopy evaporation occur, eqn. (5) provides a description of the total evaporation $\lambda E$. To obtain the component fluxes from the canopy, $\lambda E_{\mathrm{c}}$, and the soil $\lambda E_{\mathrm{s}}$, it is necessary to compute $D_{\mathrm{o}}$, the in canopy vapour pressure deficit, following Shuttleworth and Wallace (1985),

$D_{\mathrm{o}}=D+\{\Delta A-(\Delta+\gamma) \lambda E\} r_{\mathrm{a}}^{\mathrm{a}} / \rho c_{\mathrm{p}}$

$\lambda E_{\mathrm{c}}$ and $\lambda E_{\mathrm{s}}$ can now be calculated from separate combination equations

$\lambda E_{\mathrm{c}}=\frac{\Delta\left(A-A_{\mathrm{s}}\right)+\rho c_{\mathrm{p}} D_{\mathrm{o}} r_{\mathrm{a}}^{\mathrm{c}}}{\Delta+\gamma\left(1+r_{\mathrm{s}}^{\mathrm{c}} / r_{\mathrm{a}}^{\mathrm{c}}\right)}$

and

$\lambda E_{\mathrm{s}}=\frac{\Delta A_{\mathrm{s}}+\rho c_{\mathrm{p}} D_{\mathrm{o}} / r_{\mathrm{a}}^{\mathrm{s}}}{\Delta+\gamma\left(1+r_{\mathrm{s}}^{\mathrm{s}} / r_{\mathrm{a}}^{\mathrm{s}}\right)}$

In practice we do not have a direct measure of $r_{\mathrm{s}}^{\mathrm{s}}$ however, soil evaporation, $\lambda E_{\mathrm{s}}$, was measured using microlysimeters (further details are given in Wallace et al., 1990) and this was used to calculate $r_{\mathrm{s}}^{\mathrm{s}}$. The computational sequence used to obtain transpiration was then as follows. An arbitrary value of $r_{\mathrm{s}}^{\mathrm{s}}$ was chosen and total evaporation $\lambda E$, calculated using eqn. (5). $\lambda E$ was then substituted into eqn. (13) to give $D_{\mathrm{o}}$ and $\lambda E_{\mathrm{s}}$ calculated using eqn. (15). The computed and measured values of $\lambda E_{\mathrm{s}}$ were then compared and $r_{\mathrm{s}}^{\mathrm{s}}$ adjusted and the above calculation repeated until they-agreed. The resultant value of $D_{\mathrm{o}}$ was then substituted into eqn. (14) to give the desired value of transpiration, $\lambda E_{\mathrm{c}}$.

The hourly weather data required for the above calculations were recorded using an automatic weather station described by Strangeways (1972), with a modified wet and dry bulb assembly to allow thermometers to be continuously aspirated. 


\section{RESULTS}

\section{Leaf and panicle conductances}

Figure 1 shows a plot of the hourly mean stomatal conductances of the upper and lower leaf surfaces. No clear relationship existed between the upper and lower surface conductances of individual leaves so the data in Fig. 1 are for a complete range of leaf ages occurring throughout a mature canopy and indicate that, on average, the conductances of the upper leaf surfaces were about $25 \%$ lower than those of the lower leaf surfaces.

Leaves of different age and position in the canopy also had different stomatal conductances. This is illustrated in Fig. 2 which shows the diurnal variation in the total stomatal conductance (sum of adaxial and abaxial conductances) of all the green leaves in the canopy before anthesis. Conductances measured during the morning, reached $12 \mathrm{~mm} \mathrm{~s}^{-1}$ or $480 \mathrm{mmol} \mathrm{m}{ }^{-2} \mathrm{~s}^{-1}$ just after midday and declined again in the afternoon. Maximum conductances were observed in the middle part of the canopy, where the youngest fully expanded leaves occurred. This pattern of conductances within the canopy also

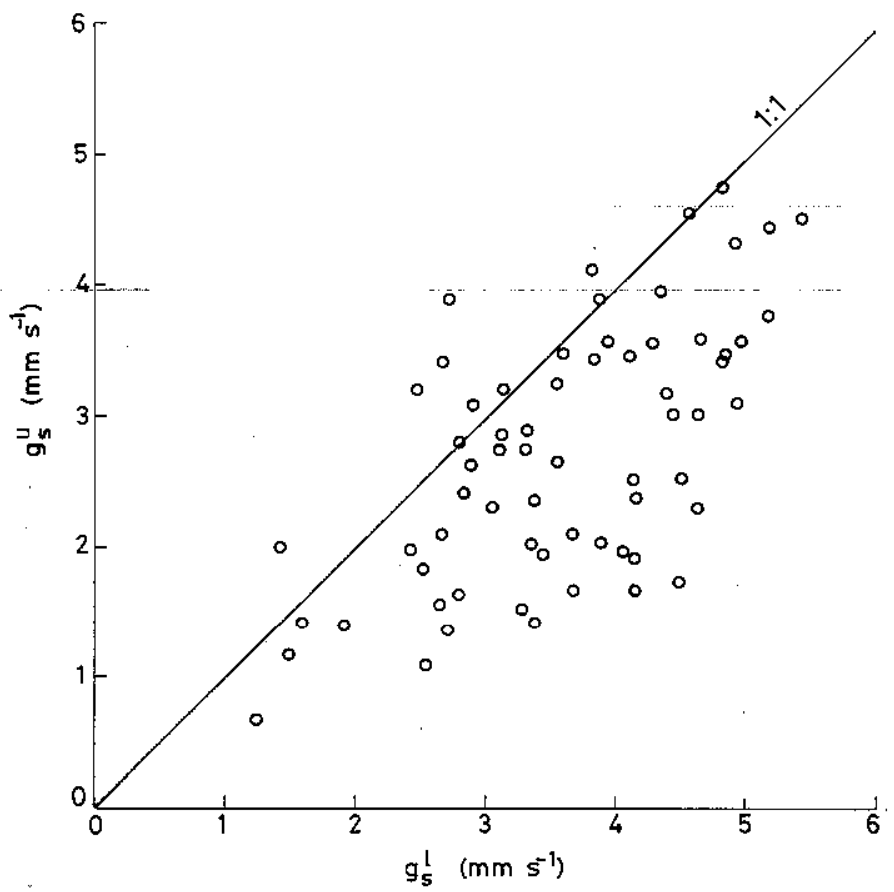

Fig. 1. A plot of the hourly mean stomatal conductances of the upper $\left(g_{\mathrm{s}}^{\mathrm{u}}\right)$ and lower $\left(g_{\mathrm{s}}^{\mathrm{l}}\right)$ surfaces of millet leaves of various ages throughout the canopy. Data are from measurements made on two days, 21 and 27 August 1986. 


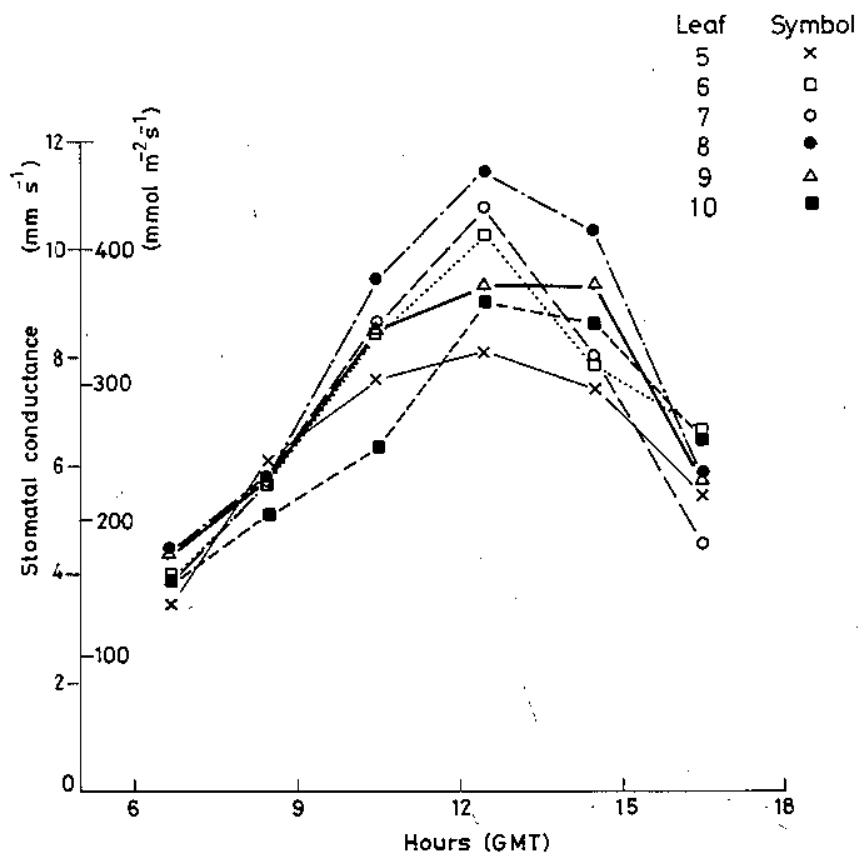

Fig. 2. Diurnal variation in the stomatal conductances of the leaves in a millet crop before anthesis; 9 July 1986.

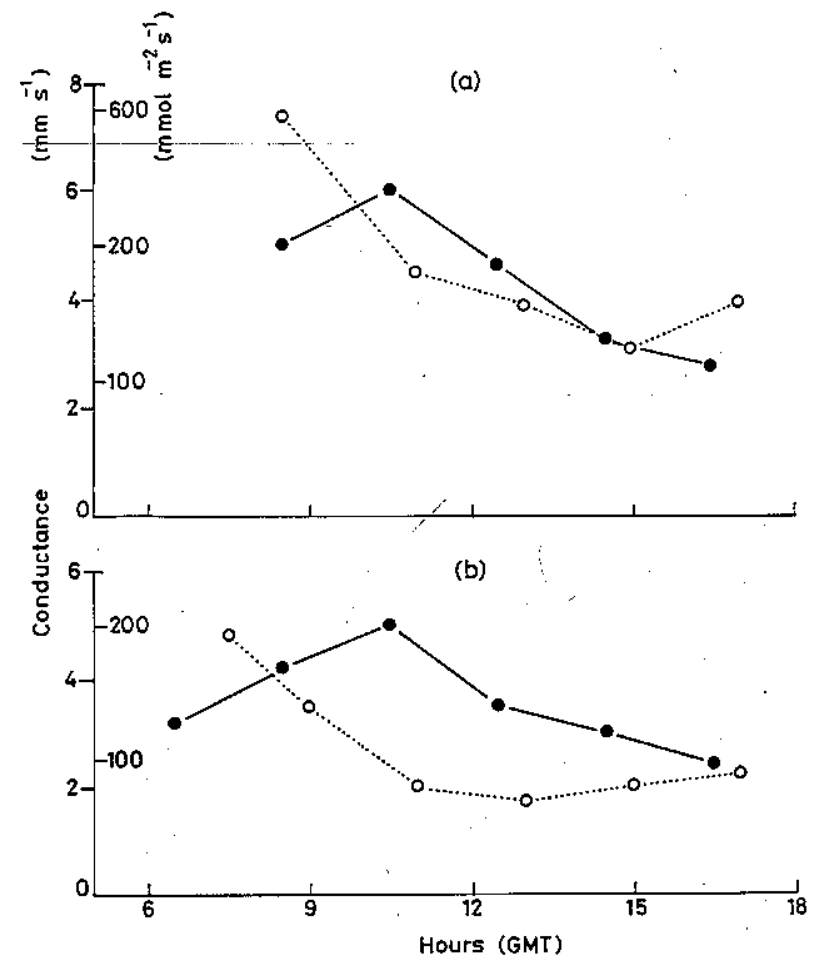

Fig. 3. Diurnal variation in the conductance of the panicle $(0 \ldots \circ)$ compared with the mean of the leaf conductances (•- ) on (a) 26 August 1987 and (b) 2 September 1987. 
occurred in the fully developed crop after anthesis, although the values of conductance were slightly lower than before.

Once the panicle has emerged it is necessary to know the contribution it makes to the total conductance of the canopy and hence to transpiration. Figure 3 shows an example of the diurnal variation in the conductance of the panicle in comparison to the mean conductance of all the green leaves in the canopy on two days in 1987. Panicle conductances were very similar to leaf conductances on 26 August 1987. In contrast, later in the season, panicle conductances were lower than leaf conductances, presumably owing to the effects of senescence on the panicles.

\section{Canopy conductance and vegetation area indices}

Figure 4 shows the total conductance of the entire millet canopy, calculated using eqn. (1), for a number of days during the 1986 season. Early in the season on 2 July, canopy conductances were very low even though the stomatal conductances were comparatively high (around $7 \mathrm{~mm} \mathrm{~s}^{-1}$ ). This was, of course, owing to the very low leaf area index at that time, only 0.23 . Leaf area increased

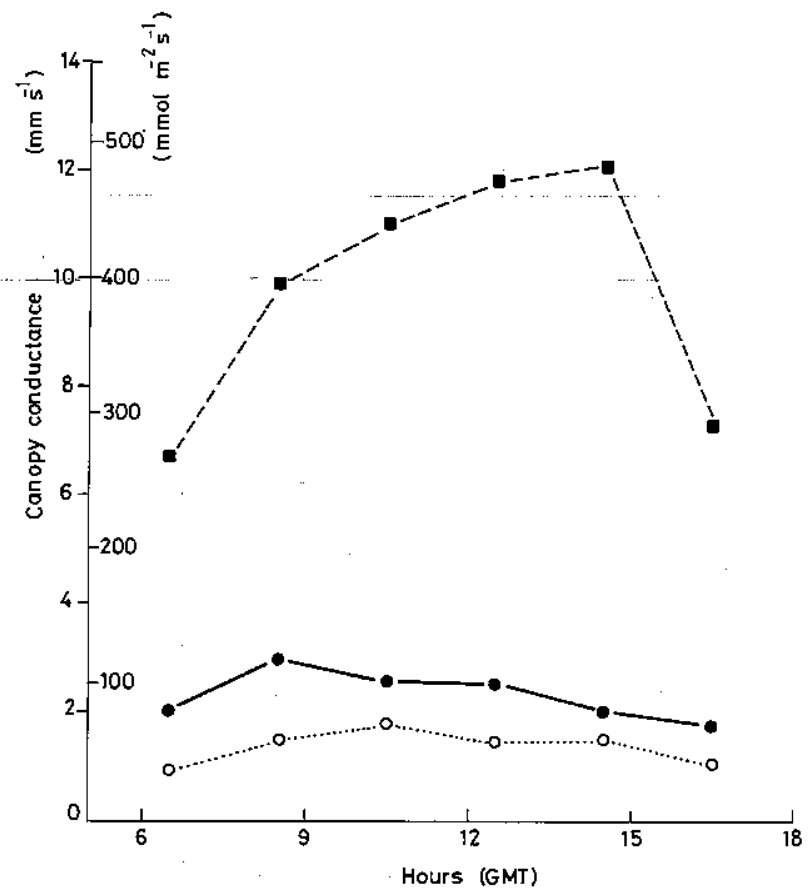

Fig. 4. The diurnal variation in canopy conductances at (a) the beginning of the season (2 July 1986, $L A I=0.23$ ), o...०, (b) mid-season (18 July 1986, $L A I=1.3$ ), $\square$ - $\square$ and (c) end of the season (27 August 1986, LAI=0.26), •-— 
rapidly during July and so by 18 July canopy conductances had increased substantially reaching $12 \mathrm{~mm} \mathrm{~s}^{-1}$, even though the leaf area index was still only a modest 1.3. As green leaf area decreased later in the season, canopy conductances also decreased so that by 27 August, canopy conductances were more like those observed at the beginning of the season.

Towards the end of the season the canopy conductance contained a contribution from the panicle. However, the maximum panicle area index measured was only 0.06 , so the panicle contribution to the canopy conductance was very small and only became significant at the end of the season when the leaf area was very low. For example, on 27 August 1986 the leaf area index was 0.26 and the canopy conductance data for this day (see Fig. 4) includes a contribution of $20 \%$ from the panicle.

\section{Transpiration}

Figure 5 shows the transpiration from the millet crop on three days at different times of the 1986 season calculated using the Shuttleworth-Wallace (1985) model. On all three days the Penman potential evaporation was very similar, between 5.5 and $6.0 \mathrm{~mm}$, but transpiration varied widely. Early in the season on 2 July, transpiration rates only reached a maximum of $0.1 \mathrm{~mm} \mathrm{~h}^{-1}$ around midday with a total of $0.9 \mathrm{~mm}$ for the entire day. Transpiration rates were much higher on 18 July reaching over $0.4 \mathrm{~mm} \mathrm{~h}^{-1}$ and giving a total loss for the day of $3.5 \mathrm{~mm}$. Towards the end of the season, as the crop senesced, transpiration rates declined again to values similar to those observed at the beginning of the season.

The difference between the transpiration values shown in Fig. 5 and those obtained using the Penman-Monteith equation (eqn. (2)) are shown in Fig. 6 . These data illustrate that for the dry soil conditions prevailing on 2 July, the Penman--Monteith equation gave transpiration values around mid-day which were about $20 \%$ lower than those obtained with the Shuttleworth-Wallace model. The effect was smaller later in the season (e.g. $3 \%$ on 18 July and $14 \%$ on 27 August), since it is dependent on the crop height (which affects the aerodynamic resistance), canopy conductance and soil wetness. Figure 7 illustrates how the differences in calculating transpiration depend on leaf area (and hence canopy conductance) and soil wetness. The ratio shown is that between the value of transpiration calculated using the Penman-Monteith equation and the Shuttleworth-Wallace equation. The example shown is for a fully grown millet crop under 'typical' midday conditions in southern Niger, i.e. net radiation $=400 \mathrm{~W} \mathrm{~m}^{-2}$, vapour pressure deficit $=25 \mathrm{mb}$, temperature $=30^{\circ} \mathrm{C}$ and windspeed $=2 \mathrm{~m} \mathrm{~s}^{-1}$. The net radiation intercepted by the canopy, surface and aerodynamic resistances are identical in both models. In high leaf area canopies the differences between the values of transpiration calculated using the two formulations is minimal. However, in sparse canopies, there are sizeable 


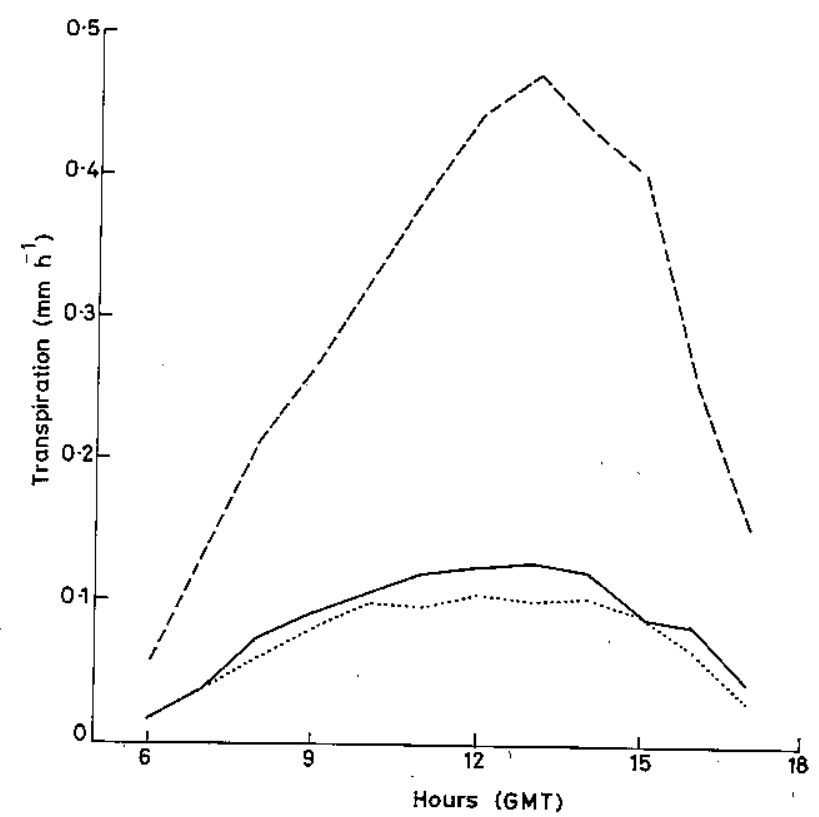

Fig. 5. Transpiration rates from millet on three different days during the 1986 season, 2 July (....), 18 July (----) and 27 August (-_- ).

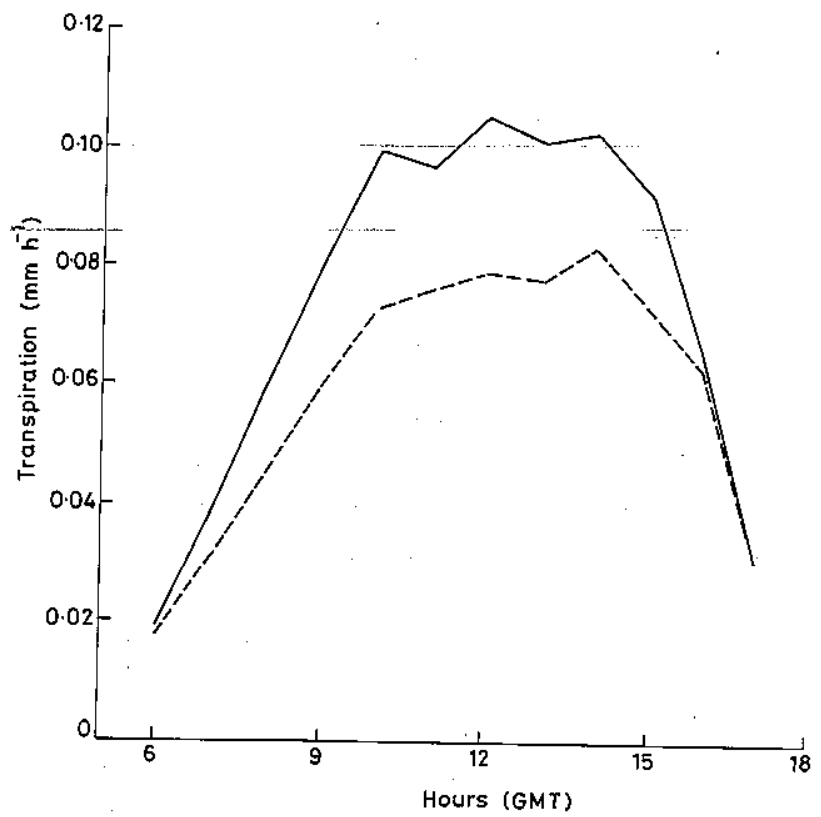

Fig. 6. A comparison of transpiration rates calculated using the Penman-Monteith (---) and Shuttleworth-Wallace equations (-). Data are for 2 July 1986 when the leaf area index was 0.23 and the crop height was $0.56 \mathrm{~m}$. 


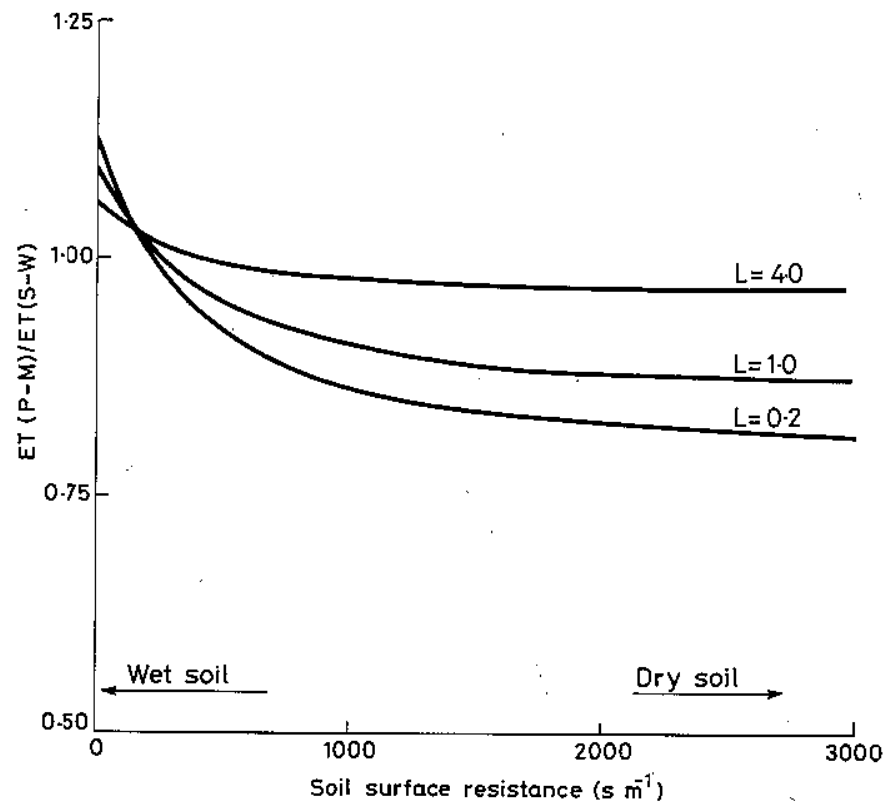

Fig. 7. Change in the ratio of transpiration calculated using the Penman-Monteith and Shuttleworth-Wallace equations, ET(P-M)/ET(S-W) with soil surface resistance. The three different lines are for a $2.5 \mathrm{~m}$ high crop with leaf area indices of $0.2,1.0$ and 4.0 under typical mid-day conditions.

systematic differences in calculated values of transpiration, with PenmanMonteith estimates higher than Shuttleworth-Wallace values when the soil is wet and vice versa in dry soil.

\section{DISCUSSION}

The values of leaf stomatal conductance found in the present study are similar to those reported in other studies of millet. For example, the observation of higher stomatal conductances on the lower leaf surfaces agrees with data reported by Squire et al. (1984) for irrigated millet grown during the dry season in India. In the present study the upper leaf surfaces were at least as well illuminated, and probably under higher insolation than the lower leaf surfaces, so the above result may be caused by lower stomatal density on the upper leaf surfaces, which has been observed in some grass species (e.g. barley and maize, see Meidner and Mansfield, 1968). Whatever the cause, it is important when estimating total canopy conductance, to measure the stomatal conductance of both leaf surfaces, since measurements on only one surface would bias the resultant canopy conductance, e.g. by $14 \%$ in the present study.

The values of total leaf conductance were quite high, up to $12 \mathrm{~mm} \mathrm{~s}^{-1}$ or 480 
mmol m$~^{-2} \mathrm{~s}^{-1}$, however, these values were recorded during the 1986 season when the rainfall was above average and hence the plants would not have been subjected to any high degree of moisture stress. However, millet has been reported to have the highest leaf conductances of all the $\mathrm{C}_{3}$ and $\mathrm{C}_{4}$ grasses (Korner et al., 1979), and has a physiological strategy which tends to maximize photosynthesis rather than to minimize water loss (Henson et al., 1982).

In the present study, maximum leaf conductances occurred at mid-canopy level rather than in the uppermost leaves. Azam-Ali (1983) reported similar values of leaf conductance and also found maximum conductances in the midcanopy layers of his sparse millet crop. However, in much denser millet crops, Henson et al. (1982) and Squire (1979) found the highest conductances at the top of the canopy. They also reported that the greatest sensitivity to atmospheric humidity was in the mid-canopy layer and that conductances varied with soil moisture (via irrigation). Clearly the exact pattern of in-canopy stomatal conductances will be determined by canopy density, weather and soil conditions.

Despite the high values of stomatal conductance, total canopy conductances were low because of the low leaf area index of the millet crop. In a sparse crop of similar leaf area index, ODA (1982) found similar values of canopy conductance which were linearly related to daily transpiration (also reported by AzamAli (1983)). However, at the same canopy conductance, daily transpiration calculated in the present study was about $50 \%$ higher than those predicted by Azam-Ali's relation between conductance and transpiration. This difference could have been caused by the higher evaporative demand during the present study (pan evaporation approximately $8 \mathrm{~mm}$ day $^{-1}$ ) compared with that during the dry season when Azam-Ali's measurements were made (i.e. pan evaporation 5-6 $\mathrm{mm}$ day $^{-1}$ ).

Systematic differences were shown to occur when calculating transpiration by the Penman-Monteith and Shuttleworth-Wallace methods. Table 1 summarizes the limits of this effect in completely wet and completely dry soil, for a crop with a leaf area index of 1.0 under 'typical' midday conditions in southern Niger. The effect is larger when the crop is short because it has a lower aerodynamic resistance. The mechanism by which these differences in transpiration occur is via the modification of the in-canopy vapour pressure deficit $\left(D_{\mathrm{o}}\right)$ owing to heat and vapour fluxes from the soil. Table 1 also shows the difference in the values of $D_{\mathrm{o}}$ implicit in the two methods. When the soil is dry the Penman-Monteith equation has a smaller value of $D_{\mathrm{o}}$ than the Shuttleworth-Wallace model, hence calculated transpiration is less using the Penman-Monteith equation. In wet soil, the reverse occurs, with the PenmanMonteith equation giving higher values of $D_{\mathrm{o}}$ and transpiration than the Shuttleworth-Wallace model. The magnitude of this effect is greatest when leaf area index is low (e.g. see Fig. 7) because the amount of energy transfer at the soil surface, and hence the degree to which $D_{\mathrm{o}}$ is modified, is largest. The mech- 


\section{TABLE 1}

The ratio (PM/SW) of transpiration calculated using the Penman-Monteith and the Shuttleworth-Wallace models under the limiting conditions of completely wet and completely dry soil. Also shown is the change in in-canopy vapour pressure deficit, $\Delta D_{\mathrm{o}}$ associated with changing from the Penman-Monteith to the Shuttleworth-Wallace models

\begin{tabular}{llllll}
\hline $\begin{array}{l}\text { Crop height } \\
\text { (m) }\end{array}$ & \multicolumn{2}{l}{ Wet soil } & & \multicolumn{2}{c}{ Dry soil } \\
\cline { 2 - 3 } & PM/SW & $\Delta D_{\mathrm{o}}$ (mbar) & & PM/SW & $\Delta D_{\mathrm{o}}$ (mbar) \\
\hline 0.1 & 1.23 & -2.8 & 0.61 & +9.6 \\
0.5 & 1.18 & -2.7 & -2.5 & 0.69 & +7.9 \\
1.0 & 1.15 & -2.2 & 0.74 & +6.7 \\
2.0 & 1.11 & -1.8 & 0.82 & +4.9 \\
3.0 & 1.08 & & 0.87 & +3.5 \\
\hline
\end{tabular}

anism which allows for modification of $D_{\mathrm{o}}$ owing to heat and water vapour fluxes from the soil is present in the Shuttleworth-Wallace model and not in the Penman-Monteith equation or any derivative of it which simply adds on the soil evaporation (e.g. Ritchie, 1972).

\section{CONCLUSIONS}

The data presented here show that for a given set of climate and soil conditions, stomatal conductances in a stand of millet vary considerably with leaf surface, age and position in the canopy. When estimating canopy conductance, it is therefore important to sample the canopy carefully in order to avoid systematic bias in the results. Furthermore, when the panicles are present, they only contribute significantly to the canopy conductance (and hence the total transpiration) at the very end of the season when the leaves are mostly senesced. Stomatal and canopy conductances also vary with weather and soil conditions, but since the climate of the region is comparatively 'constant' seasonal changes in transpiration are dominated by leaf area index via its effect on canopy conductance and radiation interception.

In sparse crops, the use of the Penman-Monteith equation ignores the fluxes of heat and water vapour which arise from the soil. It has been demonstrated that these fluxes can significantly effect the canopy vapour pressure deficit and hence transpiration, especially at the beginning of the season when the crop is short and has a very low leaf area. The Shuttleworth-Wallace model may provide an improved description of sparse canopy transpiration, but has the disadvantage that it requires a knowledge of soil surface resistance (or soil evaporation). Soil evaporation can constitute a substantial (and sometimes dominant) portion of the total evaporative loss in sparse crops (Cooper et al., 1983; Wallace et al., 1988) and cannot be ignored in the water balance. Soil 
evaporation also has an effect on crop growth since it constitutes a direct loss of water which may otherwise have been available for transpiration. On the other hand, soil evaporation is not entirely a loss, since the lowering of the incanopy vapour pressure deficit it produces can increase the water-use efficiency of the crop. This is because the amount of dry matter produced per unit of water transpired is inversely related to vapour pressure deficit (e.g. see Monteith, 1986). Again the Shuttleworth-Wallace model provides a means of assessing the effects of soil evaporation on transpiration and growth.

\section{ACKNOWLEDGEMENTS}

We would like to acknowledge the financial support of the U.K. Overseas Development Administration. We are pleased to have the opportunity to thank all the staff of ICRISAT and IH who have contributed to the success of the project.

\section{REFERENCES}

Allen, S.J., 1990. Measurement of evaporation from soil under sparse barley crops in Northern Syria. Agric. For. Meteorol., 49: 291-309.

Azam-Ali, S.N., 1983. Seasonal estimates of transpiration from a millet crop using a porometer. Agric. For. Meteorol., 30: 13-24.

Choudhury, B.J. and Monteith, J.L., 1988. A four layer model for the heat budget of homogeneous land surfaces. Q. J. R. Meteorol. Soc., 114: 373-398.

Cooper, P.J.M., Keatinge, J.D.H. and Hughes, G., 1983..Crop evapotranspiration--a-technique for calculation of its components by field measurements. Field Crops Res., 7: 299-312.

Henson, I.E., Alagarswamy, G., Bidinger, F.R. and Mahalakshmi, V., 1982. Stomatal responses of pearl millet (Pennisetum americanum [L.] Leeke) to leaf water status and environmental factors in the field. Plant, Cell Environ., 5: 65-74.

Korner, C.H., Scheel, J.A. and Bauer, H., 1979. Maximum leaf diffusive conductance in vascular plants. Photosynthetica, 13: 45-82.

Meidner, H. and Mansfield, T.A., 1968. Physiology of Stomata. McGraw-Hill, London 179 pp.

Monteith, J.L., 1965. Evaporation and Environment. In: State and Movement of Water in Living Organisms. Symp. Soc. Exp. Biol. 19th, 205-234.

Monteith, J.L., 1986. How do crops manipulate water supply and demand? Phil. Trans. R. Soc. Lond. Ser. A., 326: 245-259.

ODA Report 3208, 1982. Pearl millet: planting density, water use and productivity. Report No. 7 ODA Microclimatology Unit, University of Nottingham, School of Agriculture, $98 \mathrm{pp}$.

Ritchie, J.T., 1972. Model for predicting evaporation from a row crop with incomplete cover. Water Resour. Res., 8: 1204-1212.

Shuttleworth, W.J. and Wallace, J.S., 1985. Evaporation from sparse crops - an energy combination theory. Q. J. R. Meteorol. Soc., 111: 839-855.

Shuttleworth, W.J., Gash, J.H.C., Lloyd, C.R., McNeill, D.D., Moore, C.J. and Wallace, J.S., 1988. An integrated micrometeorological system for evaporation measurement. Agric. For. Meteorol., 43: 295-317.

Sivakumar, M.V.K., 1987. Climate of Niamey. Progress Report-1, ICRISAT Sahelian Center, Niamey, Niger. International Crops Research Institute for the Semi-Arid Tropics, $36 \mathrm{pp}$. 
Squire, G.R., 1979. The response of stomata of pearl millet (Pennisetum typhoides S. and H.) to atmospheric humidity. J. Exp. Bot., 30: 925-933.

Squire, G.R., Gregory, P.J., Monteith, J.L., Russell, M.B. and Singh, P., 1984. Control of water use by pearl millet (Pennnisetum typhoides). Exp. Agric., 20: 135-149.

Strangeways, I.C., 1972. Automatic Weather Stations for network operation. Weather, 27: 403408.

Wallace, J.S., Gash, J.H.C., Lloyd, C.R. and Sivakumar, M.V.K., 1900. Evaporation from a sparse dryland millet crop in Niger, West Africa. In: Proc. Int. Conf. Dryland Farming, Amarillo, Texas, 1988, in press.

West, L.T., Wilding, L.P., Landeck, J.K. and Calhoun, F.G., 1984. soil survey of the ICRISAT Sahelian Centre, Niger, West Africa. Soil and Crop Sciences Department/Tropsoils, Texas A and M, $66 \mathrm{pp}$. 